\section{NOVA TELLVS}

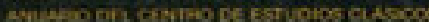

Nova Tellus

ISSN: 0185-3058

novatelu@servidor.unam.mx

Centro de Estudios Clásicos

México

GARCÍA PÉREZ, David

La tematización del mito de ĺo en Prometeo encadenado

Nova Tellus, vol. 23, núm. 2, 2005, pp. 33-68

Centro de Estudios Clásicos

Distrito Federal, México

Disponible en: http://www.redalyc.org/articulo.oa?id=59120933002

- Cómo citar el artículo

- Número completo

- Más información del artículo

- Página de la revista en redalyc.org

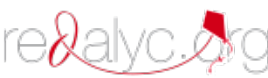

Sistema de Información Científica

Red de Revistas Científicas de América Latina, el Caribe, España y Portugal

Proyecto académico sin fines de lucro, desarrollado bajo la iniciativa de acceso abierto 


\title{
La tematización del mito de Ío en Prometeo encadenado
}

\author{
David GarCía PÉrez \\ Universidad Nacional Autónoma de México \\ prometeo@att.net.mx
}

RESUMEN: En este artículo se analiza el mito de Ío en la tragedia Prometeo encadenado, atribuida a Esquilo, con fundamento en algunos aspectos de la tematología y de la mitocrítica. La finalidad es demostrar que el autor del Prometeo encadenado reelaboró temáticamente los componentes míticos de la historia de Ío, al acoplarlos con el mito de Prometeo, fundando con ello una nueva recepción y proyección de los mitos en cuestión. Para alcanzar tal demostración, se abordan los siguientes tópicos: el debate entre democracia y tiranía por medio de las figuras de Zeus y de Prometeo, el castigo como forma de hacer justicia, y el viaje de iniciación de Ío.

ABSTRACT: This article will apply thematology and mythical criticism to analyse the myth of Io in Prometheus Vinctus - a myth which has been attributed to Aeschylus himself. The aim is to demonstrate that the author of Prometheus Vinctus mixed thematic elements of the Prometheus myth with those of the Io myth to establish a new trajectory and reception for both myths. This demonstration will involve consideration of (i) the struggle between democracy and tyranny through such characters as Zeus and Prometheus, (ii) punishment as a way of achieving justice, and (iii) the course of Io's initiation.

Palabras Clave: ío, literatura-comparada, mitocrítica, prometeo-encadenado, tematología, tragedia.

RECEPCIÓN: 6 de octubre de 2004.

ACEPTACIÓN: 2 de septiembre de 2005. 



\title{
La tematización del mito de Ío en Prometeo encadenado
}

\author{
David García PÉREZ
}

\begin{abstract}
Un mugido animal, de vaca, pero también elemental como el poderoso rumor del viento y terrible como el grito iracundo de una amante despechada.

Carlos Fuentes, "El amante del teatro"
\end{abstract}

Para elaborar su Prometeo encadenado, Esquilo tuvo a la vista, sin duda alguna, los poemas hesiódicos. La teogonía y Los trabajos y los días constituyeron, pues, las fuentes en que el poeta trágico abrevó, en primer término, para construir la vértebra de su obra teatral. Sin embargo, no hay que perder de vista otro origen temático no menos importante para la poesía dramática en general: la tradición oral de los mitos, elemento que a menudo se soslaya porque resulta casi imposible saber qué materiales conoció el autor y, en relación con los contextos histórico y mitológico, cuya frontera en algunas ocasiones se desvanece, sólo resta hacer presunciones a partir de lo que el texto en sí mismo brinda. Si bien es cierto que la poesía épica y la lírica grabaron una considerable expresión de los mitos, también lo es el hecho de que fuera de ellas se transmitió de manera oral una serie de relatos que arribaron a las puertas del teatro y, a partir de él, alcanzaron un eco temático substancialmente perenne en el marco de la literatura occidental. Puesto que siempre existirá la laguna de la tradición oral, ${ }^{1}$

\footnotetext{
${ }^{1}$ Nella forma drammatica il mito di Prometeo conserva dunque un carattere propriamente 'aperto': e poiché il Prometeo incatenato si fonda su materiali che sostanzialmente ripropongono il nucleo tradizionale del mito, occorre interpre-
} 
los cambios que se perciben en el modo en que Esquilo proyectó el mito de Prometeo y los mitemas adyacentes, como el de Ío, temáticamente pueden ser atribuibles a él,

Así, con las tradiciones oral y escrita, el poeta trágico echó mano de los materiales mitológicos existentes para crear otra visión del mito, es decir, para tematizar lo ya construido como sustancia literaria. Desde el momento en que la poesía dramática adaptó el material de los mitos a las condiciones propias del teatro, existió ya un modo en el que la recepción de los temas apuntó, por parte de los poetas, a una reelaboración natural de los mitos y a una invención de nuevas temáticas literarias. Este procedimiento se evidencia particularmente en la manera en que Esquilo abordó, recreó e innovó el mito de Ío.

$\mathrm{Si}$ los relatos orales son patrimonio y retrato cultural de un pueblo, la tradición escrita y, en especial, el teatro, como desarrollo patente del refinamiento griego, se encargaron de fijar una especie de canon mitológico cribado por el espíritu trágico. Ya Alsina ha apuntado con acierto que no existió el concepto de originalidad entre los antiguos griegos, que sería un error acercarse a los poemas griegos partiendo de esta concepción moderna. ${ }^{2}$ La contraparte de la originalidad es la mímesis, procedimiento que ha sido considerado el motor de la creación literaria a partir de la propuesta aristotélica. Hay dos modos en que la mímesis se produce: por una parte, tal como señaló Aristóteles cuando afirmaba que el poeta es imitador, de igual modo que un pintor o cualquier otro que hace representaciones, por fuerza imitará siempre de una de las tres maneras posibles, o como fueron o son, o como se dice y se cree que son, o bien, como deben ser. ${ }^{3} \mathrm{Y}$ también hay mímesis

\footnotetext{
tare questa prerogativa come una conseguenza della sua struttura formale. Del Corno, p. 36.

2 Alsina, p. 454.

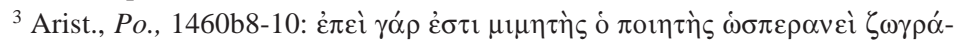

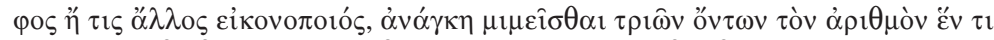

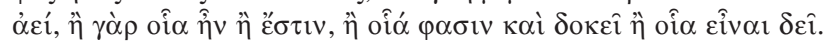


en el sentido de que se copia el modelo que se considera digno de tal hecho, y se reelaboran e incorporan nuevos elementos, ${ }^{4}$ lo cual apunta hacia los terrenos de la tematología, pues basta con pensar simplemente que el contexto definirá en mucho una nueva escritura del mito. ${ }^{5}$

Alsina también ha propuesto la posibilidad de descubrir innovaciones - no originalidad - en los autores antiguos; éstas las agrupó en técnicas, ideológicas y de orden mítico o literario. ${ }^{6}$ Habría que añadir a esta orientación, tan próxima, por cierto, a las consideraciones de la tematología en el ámbito de la literatura comparada, ${ }^{7}$ que es difícil hallar una modalidad de innovación separada de los otras dos, sobre todo en la relación que se da entre un cambio de tipo ideológico y otro de carácter mítico, pues, como se verá más adelante en la ejemplificación, la metamorfosis temática y la estructural se sustentan entre sí a partir de los materiales seleccionados para la conformación de una obra literaria. Esquilo, en efecto, fue un dramaturgo de innovaciones en cuanto al mito se refiere, tal como lo demuestra el Prometeo encadenado, que es quizás

\footnotetext{
${ }^{4}$ Cfr. Gadamer, pp. 123 y ss.

${ }^{5} \mathrm{Al}$ respecto, Trocchi, "Temas y mitos literarios", p. 136, que sigue a Trousson, afirma que la finalidad de un estudio tematológico es la de interpretar las variaciones y las metamorfosis de un tema literario a través del tiempo, a la luz de sus relaciones con las orientaciones contextuales históricas, ideológicas e intelectuales; con tal procedimiento se alcanza a dilucidar el carácter dinámico y la evolución de los temas literarios.

${ }^{6}$ Alsina, p. 455.

${ }^{7}$ Guillén, 1993, p. 191, al respecto ha escrito lo siguiente: In effect, thematology at that time usually consisted in assembling or summarizing the diverse treatments of a single topic or figure in its global manifestations, or in tracing the itinerary of a traditional myth. Y más adelante, op. cit., pp. 196-197, este mismo comparatista señala que the condition of a theme is active and passive at the same time: a provoking, integrating factor, on one hand; object of modification, on the other. Coming out of the world, from nature and culture, the theme is what the writer modifies, modulates, overturns, not what he says but what he uses to say with, whatever its extension as we noted. En este mismo tenor, cfr. Trousson; Guillén, 1985; Daemmrich.
} 
uno de los mejores ejemplos de las transformaciones que sufrieron los mitos en la poesía trágica.

Así pues, desde el momento en que Esquilo se ocupó del mito de Ío y lo vinculó con la historia de Prometeo, fue creada una serie de particularidades que indican los procedimientos de innovación temática. Este fenómeno literario es lo que aquí denominamos "tematización", es decir, la vía que sigue un mito que es reelaborado constantemente, y que se convierte en una fuente de creación e inspiración para abordar situaciones contemporáneas bajo antiguos modelos temáticos. Lo que proponemos a la luz de la tematología se corresponde con los términos estrictos de la mitología, si atendemos lo que Mircea Eliade apuntó en torno a una de las características del mito del eterno retorno:

nos hallamos frente a la concepción de una "élite" que interpreta la historia contemporánea por medio de un mito. Se trata pues, de una serie de acontecimientos contemporáneos que están articulados e interpretados conforme al modelo atemporal del mito heroico. $^{8}$

Los dos postulados anteriores, el de la literatura comparada y el de la mitología, se explican del siguiente modo: 1) Hesíodo vio en la figura prometeica una especie de mito degradado, una historia que sirvió para apuntalar los distintos argumentos que decantaron la figura de Zeus como una deidad suprema en todos los órdenes. Siguiendo la tradición que se remonta hasta Homero, el poeta beocio colocó a Prometeo en el grupo de Tersites y de Perses, es decir, en el de aquellos personajes que de un modo u otro se levantaron en contra del orden establecido y representaron potencialmente un peligro para el tan buscado cosmos. Con lo anterior, queremos remarcar que sería difícil encontrar en los poemas hesiódicos un tema que gravite

\footnotetext{
${ }^{8}$ Eliade, 1999, p. 43.
} 
alrededor de la figura de Prometeo. Si entendemos a Hesíodo, podemos afirmar que el tema dominante en sus dos poemas es la unidad expresada mediante Zeus y la Justicia $(\Delta i ́ \kappa \eta)$, mientras que la historia de Prometeo sólo es un tópico más.

2) En cambio, la resemantización que llevó a cabo Esquilo no sólo revaloró al Titán como un héroe cultural, sino que dio pie para considerar una serie de temas no tratados hasta entonces: el progreso, la rebeldía y la libertad, por lo menos. ${ }^{9}$ Esquilo, además, inventó otros mitemas y uno de ellos es el que se refiere a la amalgama con el relato de Ío. Considérese, además, que de los labios del Titán brotan las profecías en torno a la doncella. Es él quien cuenta su propia historia y la de Ío, en contraposición con el proceder tiránico de Zeus. En efecto, poco a poco el poeta describe las relaciones entre ambos personajes, teniendo como telón de fondo la crueldad e injusticia de Zeus, hasta revelar cuál es el tópico que une a estos dos personajes: de Ío habrá de nacer Heracles, el libertador de Prometeo.

Ío era una princesa de Argos, pues fue hija de Ínaco. Zeus se enamoró de ella, lo que provocó la cólera de Hera. A causa de lo anterior, la doncella sufrió una metamorfosis y adquirió la forma de una vaca que tenía que andar errante de modo precipitado en las tierras de Europa, Asia y África, hasta que finalmente habría de regresar a Tebas, de donde había partido. Su errabundez era provocada por el aguijón de un tábano que la seguía a todas partes. En Canobo, Zeus engendró en ella a Épafo, el

\footnotetext{
${ }^{9}$ Resulta categórico e ilustrativo lo anotado por Trocchi, “Temas y mitos literarios", p. 136, sobre este punto: Por lo que se refiere a la distinción [...], entre los "temas del héroe" y los "temas de situación", los primeros serían [...] los relacionados con una figura mítica que se vuelve autónoma respecto a la "situación", o al contexto narrativo que la ha engendrado, superándolo y llegando a ser la encarnación típica de una idea, a causa del alcance simbólico representado por el héroe. Es éste el caso de Orfeo o de la figura de Prometeo que, en el proceso de abstracción típico de los "temas del héroe", se van convirtiendo cada vez más en la imagen de la libertad, del genio, del progreso, de la rebelión o del conocimiento, connotada históricamente.
} 
nacido por el toque, pues, con el contacto divino, Ío retornó a su forma humana y nació su hijo. Épafo gobernó las tierras del Nilo. Cinco generaciones después, cincuenta doncellas, descendientes de Épafo, tuvieron que huir de sus primos que las pretendían. Hallaron refugio en Argos, pero tuvieron que casarse; y cuando se vieron privadas de la protección de los argivos, asesinaron a sus primos en la noche de bodas. Sólo Hipermnestra se abstuvo de cometer tal crimen, y de su esposo, Linceo, nació una nueva generación de reyes argivos. Entre los últimos descendientes de Hipermnestra y Linceo se halla Heracles. ${ }^{10}$

Resulta natural y, al mismo tiempo, innovador que Esquilo uniera el mito de Ío con el de Prometeo a través de Heracles, pues éste, como descendiente de la doncella, es quien habría de liberar al Titán. Sin embargo, lo más importante en cuanto a la reelaboración temática es que la revelación de este hecho es algo secundario en el desarrollo de Prometeo encadena$d o,{ }^{11}$ no sólo en términos narratológicos, sino también en términos de la percepción del público, porque lo que se evidencia, en primera instancia, es el dolor compartido entre los dos personajes. Uno de los elementos centrales que comparten Ío y Prometeo, y que justifica el nexo temático creado por Esquilo, es la solidaridad que se expresa entre ellos, y que se verifica en la manera en que Prometeo revela el futuro de Ío. El destino ha puesto en el camino de la injusticia a los dos personajes, y, finalmente, su suerte está unida en el futuro a través de Heracles. Mientras tanto, la solidaridad se manifiesta en el castigo y el dolor que los acompaña. ${ }^{12}$

Si Ío entra en escena para dialogar con Prometeo, este hecho sucede narratológicamente porque ella anda errabunda y

\footnotetext{
${ }^{10}$ Sobre la historia de Ío, en general, cfr. Apollod., Bibl., II, 3-4; Hdt., I, 1; Paus., III, 18; Ov., Met., I, 583 y ss.; Hyg., Fab., 145. Esquilo también abordó este mito en Las suplicantes.

${ }^{11}$ Cfr. Taplin, p. 265.

${ }^{12}$ Cfr. Conacher, pp. 17-18. El diálogo entre Ío y Prometeo, además, ha sido calificado como una de las escenas más penetrantes del teatro griego por el des-
} 
no sabe con certeza a dónde se dirige, y porque, en términos tematológicos, el dolor nacido en la injusticia cometida por Zeus la coloca en un plano similar al de Prometeo, con la diferencia de que ella es una simple mortal. Así pues, el tópico de Heracles es un asunto del que se ocuparía la tercera parte de la trilogía. ${ }^{13}$

Hay que considerar, pues, que Esquilo fue con seguridad el primer autor que mezcló temáticamente el mito de Ío con el de Prometeo. Al mismo tiempo, el resultado de tal mezcla constituye la primera fuente a la que es posible atenerse sobre el tópico del futuro liberador del Titán, con lo que queda soldado el nexo entre Ío y Prometeo, pues de acuerdo con Hesíodo, éste no sería liberado, según la voluntad de Zeus:

pues ni el hijo de Japeto, el bienhechor Prometeo, de aquél evitó la grave ira, empero por fuerza, aunque fuera muy cuerdo, lo retiene una firme cadena. ${ }^{14}$

pliegue de los sentimientos y las razones que unifican a los personajes en torno al sufrimiento que padecen a causa de Zeus. Así lo han manifestado Croiset, pp. 149, 151-152; Duchemin, pp. 191-192; Reinhardt, p. 73.

${ }^{13}$ Para la Antigüedad no había duda de que Esquilo era el autor del Prometeo encadenado. Dicha tragedia se ha transmitido dentro de las siete obras de este poeta que se conservaron en la tradición manuscrita, que procede del códice Mediceus Laurentianus del siglo xI d. C. Junto con esta tragedia conservada se mencionan, además, otras piezas dramáticas esquileas que tienen que ver con el mito prometeico: Prometeo liberado, Prometeo portador del fuego y Prometeo encendedor del fuego. Esta última composición puede ser otro título de la segunda obra citada. Si se considera que las tres obras existieron, estaríamos frente a una trilogía como la Orestiada. Por lo que se sabe, de los poetas trágicos griegos, Esquilo fue el único que utilizó el encadenamiento de varias piezas dramáticas para bosquejar los temas míticos, pues esta característica no se encuentra ni en Sófocles ni en Eurípides. No obstante, se piensa que también pudo existir una dilogía formada sobre los temas del castigo y de la fortuna de Prometeo. Para filólogos como Lloyd-Jones, la trilogía estaría completada por una obra perdida. Cfr. Hogan, p. 274; García Gual, pp. 131 y 133; Alsina, "Esquilo", en López Férez, pp. 298-299; De Romilly, pp. 36, 62-63. Solmsen, p. 126, n. 8, supone que Prometeo portador del fuego sería la tercera pieza de la trilogía, no la segunda.

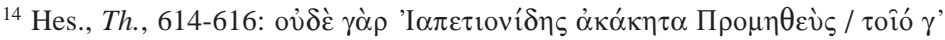

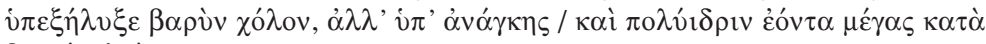

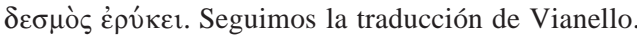


La condena de Hesíodo sugiere el cierre del relato en el sentido de que no hay posibilidad de salvación para Prometeo. Una vez que el Titán ha sido condenado, se paga la afrenta que sufrió Zeus, lo que queda de manifiesto con las cadenas que lo atan. Sin embargo, hay que advertir que, según la versión hesiódica, Heracles habría liberado al Titán, del suplicio del águila, no de las cadenas, por lo que el Prometeo hesiódico, entonces, permanece atado y prisionero para siempre. Sólo después el mito fue modificado en Atenas (cf. la tragedia perdida de Esquilo, intitulada "Prometeo liberado"), porque resultaba alli insoportable que el muy venerado Prometeo, civilizador, quedara como eterno enemigo y prisionero de Zeus. ${ }^{15}$ Entonces, tal como apuntó Wilamowitz, la introducción de Heracles en el mito de Prometeo es una adaptación de Esquilo, ${ }^{16}$ que de este modo trazó una línea narrativa que se aparta del relato hesiódico para revalorar las virtudes prometeicas. La adaptación del material mítico sólo se puede dar en la medida en que se transforma radicalmente una de las directrices tópicas, al punto de que se puede afectar el mismo sentido temático, tal como ocurre entre las versiones de Hesíodo y de Esquilo sobre el Titán. El mito de Ío funcionó, entonces, como el ingrediente que modificó de modo sustancial la recepción del mito prometeico en la visión esquilea, como veremos en seguida.

\footnotetext{
${ }^{15}$ Vianello, "Notas al texto español", en Hesíodo, Teogonía, p. CCCLV, nota a los vv. 523-533; la filóloga apunta, además, que tales versos han sido considerados espurios, porque su sentido contradice al v. 616 .

16 Wilamowitz, p. 130: Auch den Adler als Peiniger und den Herakles als Erlöser fand Aischylos in der Theogonie; Zeus gibt aus Rücksicht auf seinen Sohn nach. Dies ist ohne jeden Zweifel eine Nachdichtung, denn die Geschichte schließ

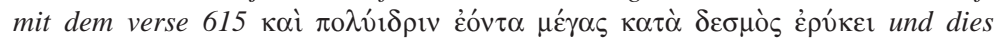
Präsens läßt sich nicht wegdisputieren. Es liegt auch durchaus in der Tendenz des Hesiodos, daß die alte ungeschlachte Göttergeneration durch Zeus beseitigt wird. Das ist von höchstem Werte für die Beurteilung der Sage, aber für Aischylus einerlei, der die Kritik an dem Texte der Theogonie so wenig üben konnte wie es das Altertum überhaupt getan hat. Cfr. también Croiset, pp. 155-156.
} 
Tres elementos saltan a la vista en el momento en que se percibe el nexo que Esquilo dispuso al reelaborar el mito en Prometeo encadenado: en primer término, dos historias mitológicas mudan algunos de sus tópicos, lo cual conduce, en segundo lugar, a la alteración de su contenido esencial, y esto, a su vez, formula una nueva tradición temática. En tercer lugar, la exposición esquilea pone de manifiesto el contexto en el que se producen tales cambios, es decir, la transición política de la tiranía a la democracia en el marco del cosmos divino, que es el espejo de una realidad histórica concreta que vivían las poleis griegas en el siglo v.

Antes de arribar al punto concreto en el que Prometeo revela a Ío que de ella nacerá su libertador, las profecías y los relatos del Titán han descrito profusamente la violencia que tanto él como la doncella están padeciendo a causa de Zeus. Así pues, el asunto de la justicia en el mito opera como uno de los puentes que permite dilucidar el modo de tematización del mito de Ío. En Prometeo encadenado, la mayoría de los personajes son dioses, con excepción de Ío, y esto expresa cómo la justicia de Zeus se da tanto en el nivel de los dioses como en el de los humanos, a partir del momento en que se organiza un nuevo gobierno bajo la regencia del Cronida. Hay que notar que tal justicia se identifica con la ausencia absoluta de libertad, dado el terror con que se avasalla a los personajes, lo que lleva a Hefesto a afirmar que libre nadie es, sólo Zeus. ${ }^{17}$

A partir de lo anterior, es posible sugerir, entonces, que la doncella con forma de vaca representa la tensión entre el mundo de los dioses y el de los hombres en torno a la idea de justicia y de libertad, y que, cuando ella dialoga sobre este punto con Prometeo, hay un eco del pensamiento hesiódico en lo que se refiere a los vínculos que se generarían entre hombres y dioses a partir del sacrificio en Mecona. Al respecto, Duchemin ha hecho notar que

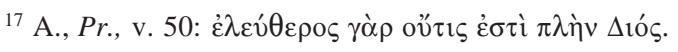


la Justice en effet doit s'instaurer d'abord entre les dieux, sans quoi elle ne pourrait régir les rapports des dieux et des hommes ni ceux des hommes entre eux sous le regard des dieux. L'itinéraire spirituel d'Eschyle débouche sur un effort intense pour élucider ce problème fondamental du monde, le problème de la Justice. ${ }^{18}$

En Los trabajos y los días, Hesíodo cuenta el desarrollo de los hombres a través del mito de las cinco razas. Cada una de ellas va en orden decreciente, de acuerdo con la actitud que los hombres tomaron ante la justicia y el orden divinos, hasta llegar a la época de Hesíodo, quien no percibió un mejor porvenir mientras los seres humanos siguieran observando una conducta distinta a la marcada por Zeus. Pues bien, los hombres que asistieron al sacrificio primigenio en Mecona, lugar donde sus derechos y obligaciones iban a ser marcados separadamente respecto de los dioses — tales hombres corresponden con seguridad a la tercera raza, la de bronce, mencionada por Hesíodo_- ${ }^{19}$ llevaron a cabo el rito correspondiente para pactar con el Cronida, en tanto que éste era el nuevo gobernante del Olimpo. ${ }^{20}$

En el marco del tiempo mítico, el advenimiento del reino de Zeus del que habla Hesíodo coincide con el señalamiento reiterativo en Prometeo encadenado de que el Cronida apenas se ha hecho del poder. ${ }^{21}$ Entonces, de acuerdo con la perspectiva mítica, el castigo que Zeus impuso a los hombres, según

\footnotetext{
${ }^{18}$ Duchemin, p. 188.

${ }^{19}$ Vianello, "Introducción", en Hesíodo, Los trabajos y los días, pp. L-LII.

${ }^{20} O p$., v. 156; Vianello, en Hesíodo, Los trabajos y los días, p. XLVIII.

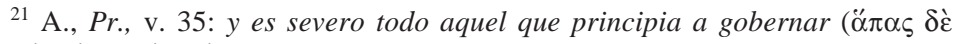

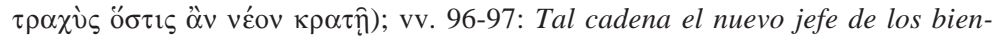

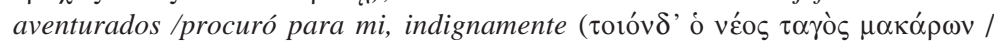

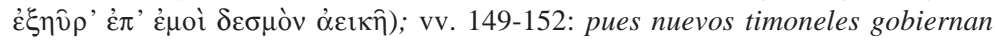
el Olimpo / y, además, con renovadas leyes / Zeus, ilícitamente, manda, / y los

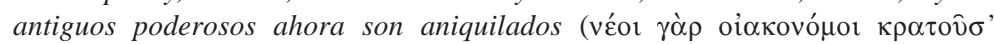

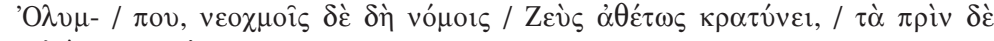
$\pi \varepsilon \lambda \omega ́ \rho 1 \alpha$ vôv $\alpha \dot{1} \sigma \tau 0 \hat{)})$
} 
la versión de Esquilo, se manifiesta en un sentido diferente al de Hesíodo, pero al mismo tiempo complementario, si se atiende el tópico de la represión que padece Ío.

El sacrificio en Mecona habría servido justamente para marcar con claridad la división entre hombres y dioses, pues, como indica Paola Vianello, "en su origen, la humanidad creada por los dioses era casi igual a sus demiurgos". ${ }^{22}$ Las posteriores repeticiones del sacrificio, tal como sucede con todos los ritos, cumplirían con la función de rememorar ese principio de división. Tal parece, pues, que la idea de sacrificio en el mito prometeico cumplió específicamente con el establecimiento del orden inmortal versus el cosmos mortal y de la justicia deificada en Zeus, y que, además, y seguramente por otras vías mitológicas y religiosas, el sacrificio cumplía también con la función de alimentar a los dioses.

En Prometeo encadenado hay una transformación sustancial del modo en que Zeus representa la justicia, en relación con las otras tragedias de Esquilo. La esencia de la justicia, tal como fue pensada y transmitida por Hesíodo y por Solón, siguió vigente en el teatro esquíleo, a excepción del Prometeo encadenado, en donde parece haber un retroceso en el modo de hacer e impartir justicia desde el Olimpo. ${ }^{23} \mathrm{Si}$ bien es cierto que en Esquilo se aprecia un proceso en el que la tragedia que principia en el caos termina por convertirse en cosmos, pues, al final hay una reconciliación entre los actores del agón, ${ }^{24}$ la pacificación no evita que Zeus sea visto como tirano y como un dios injusto, que sólo después evolucionaría a una deidad más justa o democrática. La prueba de ello es Ío, quien, contra su voluntad, habrá de convertirse en una diosa. Y esto sugiere que el cosmos sería recuperado, pero en el transcurso de tal restauración la doncella ha sido llevada a un mundo salvaje, es decir, ha

\footnotetext{
22 Vianello, en Hesíodo, Los trabajos y los días, p. XLI.

${ }^{23}$ White, pp. 108-109.

${ }^{24}$ Cfr. Kitto, pp. 17-18.
} 
sido puesta en el camino de un viaje iniciático donde perdería lo que le resta de su condición humana, pero, sobre todo, se ha encontrado con Prometeo, que simboliza también aquella parte humana que no es reintegrada al cosmos. Además, se sabe que en Prometeo liberado era posible la concordia entre Zeus y el Titán, pero, en lo que respecta a la historia de Ío, todo queda en el plano de la hipótesis, si sólo se atiende a la creación esquilea que nos resta de manera íntegra.

Ío sufre de manera gratuita, pues no ha cometido falta alguna. No ha llevado a cabo ningún delito, más que el de haber provocado el deseo carnal en Zeus. Hay que advertir que, en las obras de Esquilo, hay una diferencia tópica en torno a quién es el causante de la transformación de Ío, que la conduce a la desgracia de andar errabunda, lo cual tiene un peso específico cuando se interpreta la función de la justicia bajo la tiranía de Zeus. En Las suplicantes, Esquilo siguió la versión tradicional del mito: la culpable de las desgracias de Ío, fue Hera; en cambio, en Prometeo encadenado, el asunto se presenta ambiguo porque, si bien es cierto que la diosa es la que lanza los castigos sobre la doncella, en el fondo todo se debe a la pasión de Zeus, a lo que se suma la injusticia de la desagradable odisea a la que se ve sujeta, en este caso sí por culpa del Cronida. ${ }^{25}$

Si se comparan las acciones, frente a Prometeo, la doncella aparece libre de toda culpa, justificada o no, lo que resulta contrastante en cuanto Esquilo pone a dialogar a ambos personajes. El proceder del Titán se justifica porque salvó a la humanidad de vivir salvajemente. Hay, pues, un motor del castigo que le impuso Zeus: el engaño en el reparto de las carnes del sacrificio, el hurto del fuego, el oponerse, en fin, a los designios del Cronida. Pero, ¿qué sucede en el caso de Ío? Nada. La hija de Ínaco padece una serie de males gratuitos. Y es castigada

\footnotetext{
${ }^{25}$ Conacher, p. 17, sostiene que el causante directo de los males de Ío es Zeus. En cambio, De Romilly, 1973, p. 85, apunta en su lectura que la responsabilidad de las desgracias de la doncella es tanto de Hera como de Zeus.
} 
también de un modo que resulta profundamente doloroso. Zeus procede como un tirano que aplica sus designios violentando la voluntad ajena. Así, con causa o no, justificada o no, el castigo se comprende como la impartición de una justicia que se aprecia mediante un mal y se aplica de modo violento.

La violencia a la que Ío se ve sometida cobra vida tanto por

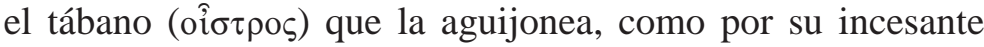
andar errante (A., Pr., v. 573: $\pi \lambda \alpha v \alpha \underline{\alpha}$, v. 577: $\tau \eta \lambda \varepsilon \dot{\varepsilon} \pi \lambda \alpha \gamma \kappa \tau$ o

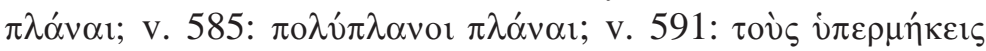
$\delta \rho o ́ \mu o v \varsigma)$ que es incitado por el mismo insecto. Uno y otro símbolo del castigo van de la mano, pues la tortura del tábano es el motor de los movimientos irrefrenables que llevan a Ío de un lugar a otro. Así como Prometeo luego será atormentado por el águila que Zeus enviará, del mismo modo el tábano cumple con el cometido de hacer sufrir a la doncella. Hay que tener en cuenta que, además del dolor físico que implican las picaduras del aguijón, para Ío el futuro se presenta incierto, inseguro y peligroso. Incluso, las revelaciones de Prometeo no la tranquilizan, como el mismo Titán le había advertido, sino que serán motivo para que, junto con el tábano, el miedo sea también un acompañante aparentemente perpetuo de Ío. ${ }^{26}$

Ahora bien, por medio del signo del castigo, Ío representa a la humanidad que, bajo el gobierno de Zeus, sufrirá una serie de males semejantes a los que padece la doncella. En efecto, si bien es cierto que los hombres pueden continuar su vida bajo la égida de Zeus, también lo es que su destino no será nada agradable. La maldad de los dioses - la envidia, habría dicho Heródoto- ${ }^{27}$ se manifiesta a través de su violencia (Kó́ que se aplica a Prometeo, filántropo, a la doncella, humana, y es el mismo dolor que experimentan los mortales.

\footnotetext{
${ }^{26}$ Cfr. De Romilly, 1971, pp. 83 y ss.

${ }^{27}$ Hdt., I, 32, 1: Pero él [Solón] objetó: -Creso, me preguntas sobre cuestiones humanas y yo sé que la divinidad es, en todo, envidiosa y causa de perturbación. Cfr. también VII, 10.
} 
Al ser Ío la única mortal que emerge en esta tragedia, de las otras dos piezas se puede colegir que no hay rastro de participación de los seres humanos. ${ }^{28}$ Esto apunta ya a una peculiaridad en el caso de la hija de Ínaco, pues sólo este ser humano es quien tiene un contacto estrecho con los dioses en la representación esquilea. Ella, entonces, es la imagen de los mortales en un pleito entre dioses. Al ser castigada, la humanidad entera sufre la violencia que Zeus ejerce, pues, bajo su reinado, hay un plan que apunta al exterminio de la raza humana que fue abortado por la intervención rebelde de Prometeo:

En cuanto en el trono paterno se sentó, al punto otorgó privilegios

a los demás dioses y así organizó

su gobierno; pero de los miserables mortales su palabra no tomó en cuenta; al contrario, aniquilando esta raza totalmente, deseaba engendrar otra nueva.

Y contra estas cosas nadie se opuso, excepto yo, yo sí me atreví y liberé a los mortales de no ser exterminados al ser enviados al Hades. ${ }^{29}$

Así pues, no sólo la voluntad de Zeus expresada por el castigo como medio de justicia se hace patente en Prometeo y en Ío. En todo caso, no existe la intención manifiesta de deshacerse de estos dos personajes, en cambio del hombre sí. En efecto, esto último sería una justificación para el proceder desmesurado de Zeus. La intención del Cronida de destruir a los mortales llevó a White a afirmar que the crucial question, then, is not why Prometheus helped mortals, but why Zeus punishes

\footnotetext{
${ }^{28}$ Para De Romilly, 1973, p. 62, Prometeo encadenado es una pieza en donde sólo participan seres divinos; se infiere, entonces, que esta filóloga considera a Ío, en el espacio de esta tragedia, como una deidad.

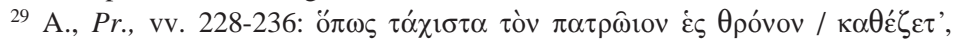

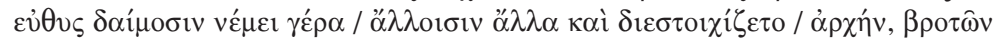

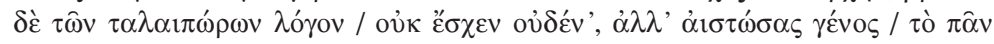

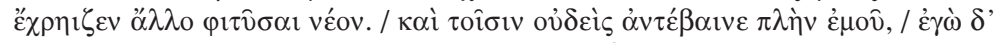

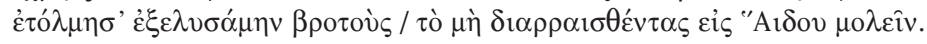


him. The play does little to clarify the Titan's aims and motives. But we hear about Zeus's plans repeatedly, albeit obliquely. ${ }^{30}$

Sin duda, el teatro de la Grecia antigua cumplía una función mimetizadora de los sentimientos; así, Ío sufre por el público y éste sufre en ella: Hence there can be no question where the symphaties of an Athenian audience must have lain -or, indeed, of any popular audience - when Prometheus breaks off his prediction of Io's future agonies with the impassioned cry. ${ }^{31} \mathrm{El}$ mito de las cinco razas expuesto por Hesíodo parece confirmar el eterno padecimiento de todo ser humano. Sin embargo, la descendencia de Ío, aquella que regirá después en Tebas, es un tópico de suma importancia porque sugiere que hay una purificación del hombre, el hombre nuevo que finalmente, en la figura de Heracles, habrá de liberar a Prometeo, y éste, al hacer la paz con Zeus, finiquitaría, de algún modo, las rencillas entre los dioses y los hombres. De cualquier manera, bajo las características del mito del eterno retorno, el hombre nuevo que sería creado por Zeus, con el paso del tiempo decaería para iniciar el camino del retorno. Aunque no se menciona explícitamente, se infiere que el mundo de los dioses también está sujeto al vaivén del retorno, pues las sucesiones en el trono supremo así lo confirman. La profecía que Prometeo tiene bajo resguardo sobre quién habrá de destronar al Cronida es la comprobación de estos supuestos.

Hesíodo narró la historia de las razas hasta llegar al punto en el que él vivía, es decir, la raza de hierro, que es el espejo de la decadencia socio-económica del hombre en la época de la aristocracia. La reconfiguración del ser humano por medio de la justicia es algo que no sucede todavía en el Prometeo encadenado, pero el problema ya había sido denunciado por Hesíodo,

\footnotetext{
${ }^{30}$ White, p. 110.

${ }^{31}$ Thomson, p. 232.
} 
por lo que cabe suponer que, al momento de tematizar el mito de Prometeo, surge la doble vía del tiempo en la contemporaneidad de Esquilo: por una parte, la injusticia es algo que se identifica con la tiranía en el marco de la democracia y, por otro lado, como consecuencia de lo anterior, hay un desfase entre la evolución política y las ideas religiosas. ${ }^{32}$

El castigo injusto de Ío representa la discrepancia entre política y religión: Zeus se ha quedado atrás en el modo de impartición de justicia, y el hombre común y corriente ha encontrado otros discursos, como la democracia, la ley y la política, para dirimir sus controversias y, así, poder progresar. ${ }^{33}$ Al final del mito, si admitimos que el cosmos será reestablecido, Prometeo y Zeus volverán al status quo anterior al sacrificio en Mecona y al hurto del fuego; Ío, como afirma la profecía, tendrá un hijo de Zeus, quien habrá de extender en los tiempos el nombre de su madre y será semilla de numerosos y connotados reyes. Ío, finalmente, habrá realizado un rito de paso extenso y doloroso bajo un esquema que Mircea Eliade ha definido, en general, para explicar que el camino es arduo, está sembrado de peligros, porque, de hecho, es un rito del paso de lo profano a lo sagrado, de lo efímero y lo ilusorio a la realidad y a la eternidad; de la muerte a la vida; del hombre a la divinidad. ${ }^{34}$ Luego del tránsito acerbo, el cosmos es instaurado para empezar inmediatamente la caída, y así se genera un eterno retorno.

Ahora bien, en el hic et nunc de la representación trágica, Ío y Prometeo son el foco que simboliza el desfase político y religioso que se produce a través de una justicia violenta. En

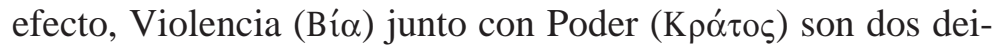

\footnotetext{
${ }^{32}$ Sobre la figura del tirano y su relación con la actividad teatral, cfr. Lanza.

${ }^{33}$ Un claro ejemplo de la evolución política que va aparejada del cambio sobre la impartición de justicia se encuentra plasmado en el mito de Prometeo, recreado en el Protágoras de Platón.

${ }^{34}$ Eliade, 1999, pp. 25-26.
} 
dades que denotan las cualidades del tirano; de hecho, Violencia es, en la poesía hesiódica, una réplica de Fuerza, una especie de unidad que se desdobla. ${ }^{35}$ Zeus es un tirano que gobierna con estas dos cualidades sobre hombres y dioses; todos están bajo su dominio, nadie escapa a su voluntad. Como ha señalado García Gual, ${ }^{36}$ el mundo regido por Zeus está colmado de hechos que se realizan "por violencia" y "con

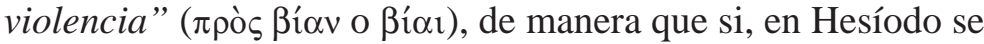
hablaba de la inteligencia o de la astucia, en la tragedia esquilea lo que sobresale son los términos Fuerza y Violencia como atributos de la justicia del Cronida. Queda la certidumbre de que Zeus no se guía ni por la prudencia ni por la sabiduría, mientras que Prometeo sigue, en esa versión, conservando sus cualidades como una deidad filantrópica y astuta, pues él sabe la manera en que habrá de terminar el reinado de Zeus, en tanto que éste lo desconoce.

Con esta violencia, el tirano ejerce el poder y aplica la justicia. Esto se evidencia cuando la doncella le pide a Zeus la muerte: con fuego incéndiame, o con tierra sepúltame, o a las marinas bestias entrégame como alimento. ${ }^{37} \mathrm{El}$ mismo Prometeo ya había invocado un final semejante al que Ío pide: iOjalá que [Zeus] a mí bajo la tierra, más abajo que el Hades que alberga a los muertos, al infinito Tártaro me mandara. ${ }^{38}$ Ambos personajes anhelan, pues, la muerte, y este deseo no sólo nace por el dolor físico que entraña su respectivo castigo, sino también porque se trata de una situación injusta: el verdadero castigo para Ío se halla en vivir errante acosada por el tábano, mientras que el morir es el remedio a sus males. En

\footnotetext{
${ }^{35}$ En la representación trágica tal vez eran personificados de manera idéntica, pues incluso Bía permanece callada y por ella habla también Kratos. Cfr. Rosenmeyer, p. 58; García Gual, p. 115.

${ }^{36}$ García Gual, p. 114.

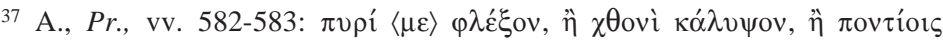

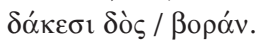

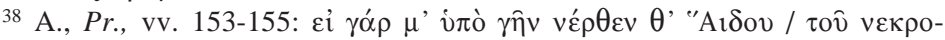

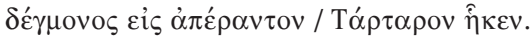


cuanto a Prometeo, el vivir atado a la roca y el estar expuesto ante el mundo son la respuesta a su osadía de confrontar a Zeus; el remedio de la muerte no le es posible porque es un dios. Por esta razón y para hacer más profunda e irónica la tragedia, su petición de ir al Tártaro se cumplirá, ${ }^{39}$ pues no sólo quedará atado a la roca, sino que junto con ella bajará al reino de los muertos, a pesar de estar vivo y de ser un dios.

Así pues, la violencia que sufre Ílo se corresponde temáticamente con el castigo que padece el Titán en los tópicos que sustentan la petición de muerte de la doncella. El fuego robado es, a final de cuentas, el mismo que incendia metafóricamente al mismo Prometeo, ${ }^{40}$ así como la hija de Ínaco debe sufrir su peregrinaje. El malestar del Titán es el águila que le devora su hígado, del mismo modo en que el tábano acosa a la doncella, y, finalmente, cuando Prometeo es sepultado en el inframundo, se expone el hecho de que es enviado al mundo de los muertos alguien que por su naturaleza no moriría. La historia de Ío se produce debido al deseo carnal que ésta ha provocado en Zeus, hecho que es la semilla del caos, pero sólo para ella. Después de un sufrimiento que parece interminable, Ío se convertirá en la consorte de Zeus: los robles parlantes, que claramente y sin ninguna clase de enigmas te saludaron como a la que va a ser la ilustre esposa de Zeus. ${ }^{41}$ El final de Ío ha sido profetizado y después de tanto sufrimiento habrá de hallar el reposo, paradójicamente junto al mismo Zeus, con lo cual su ciclo se cierra completamente.

Es proverbial el modo en que Esquilo resuelve el problema de la impartición de justicia en sus obras; ${ }^{42}$ Prometeo encade-

\footnotetext{
${ }^{39}$ A., $P r$., vv. 1080 y ss.

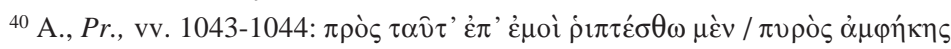

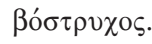

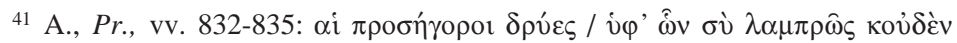

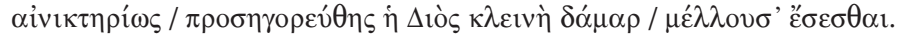

${ }^{42}$ Sobre este punto, cfr. Lloyd-Jones, "Zeus in Aeschylus", pp. 55, 57; White, pp. 108-109.
} 
nado, sin embargo, deja este asunto en suspenso y habría que suponer que, en la tercera parte de la trilogía, Prometeo sería liberado, e Ío, convertida en diosa. En la Orestiada, el poeta colocó muy bien las medidas en la balanza para que todo quedara resuelto de modo armónico; la justicia imaginada y pretendida por Hesíodo y por Solón resultó en el teatro de Esquilo un elemento activo en el devenir de las relaciones entre hombres y dioses. De manera contraria, en el Prometeo encadenado se observa que la violencia, ejercida como un modo de gobernar por parte de Zeus, se acentúa, de manera que se da la impresión de que la ira de Zeus no se detendrá. El Cronida parece desconocer los mecanismos de la justicia, mientras que el resto de los personajes, con Prometeo e Ío al frente, sí tienen una noción clara de aquélla, y es este conocimiento lo que da pie para juzgar los actos del nuevo gobernante. Paradójicamente los súbditos tienen un mejor conocimiento de lo que es la justicia, a diferencia del tirano que resuelve los asuntos sin prestar atención a nadie ni considerar nada.

Si bien es cierto que sólo conservamos una pieza completa, la segunda de la trilogía que habría conformado el mito de Prometeo, ${ }^{43}$ también lo es el hecho de que, a nuestro juicio, esta tragedia, por sí sola, contiene elementos temáticos suficientes para sugerir que el sentido de la justicia, de acuerdo con el autor, toma en cuenta otro tipo de valores que no aparecen en las demás piezas que de él conservamos. A nuestro juicio, Prometeo encadenado expresa una clara significación del reacomodo mitológico y religioso en el marco de una sociedad democrática y con una cultura críticamente propositiva, gracias, entre otras cosas, a las nuevas ideas de la sofística.

El sentido profundo y durativo del castigo es palpable cuando en éste se acumulan más elementos, y parece que la concordia no será jamás posible. El castigo transita a través de la

\footnotetext{
${ }^{43}$ Cfr. supra, n. 13.
} 
profundidad y de la duración de los hechos impuestos por el Cronida. La tragedia física, por su parte, se hace efectiva con el aumento de cada una de las cosas que viven y habrán de vivir tanto Ío como Prometeo. Cuando parece que ya no es posible recibir más castigo, se presenta otro más que remarca el anterior y hunde al personaje en un pozo profundo de dolor. $^{44}$

Tal duración y profundidad del castigo como características de la justicia de Zeus, se observa en el viaje de Ío, que, a nuestro parecer, es el otro gran componente de la resemantización de las historias de Prometeo y de la hija de Ínaco en una variante única. En efecto, uno de los elementos naturales del mito del viaje es el modo en que la reproducción de las historias parecería infinita.

Así como las aventuras de Odiseo pueden llegar a ser tantas como quiera y pueda la capacidad del mitógrafo — del aedo, propiamente-, pues no hay una secuencia lineal del relato, sino que ésta es circular y por ello se amplían las posibilidades narratológicas, ${ }^{45}$ del mismo modo en este rasgo hay que inscribir el viaje aparentemente interminable de Ío. Esto quiere decir que en Prometeo encadenado se aplicó este principio de la mitología, cuando el poeta trágico introdujo el pasaje en que el Titán es visitado por Ío. En su itinerario, la doncella puede tener tantos encuentros como sean posibles, castigada como está a andar errante por muchos lugares de modo incesante, ${ }^{46}$ antes y después del hic et nunc de la tragedia alu-

\footnotetext{
${ }^{44}$ Así, por ejemplo, Hermes anuncia a Prometeo los males que le sobrevendrán, si no revela la boda que marcará el derrocamiento de Zeus (A., Pr., vv.

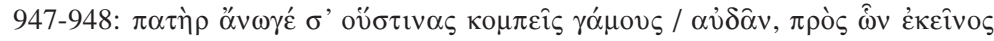

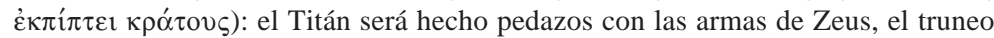
y el rayo; quedará incrustado en la roca en donde lo ató Hefesto y será sepultado junto con ella, y, cuando vuelva a la luz, su hígado será devorado por el águila del Cronida (cfr. A., Pr., vv. 1014-1035).

${ }^{45} \mathrm{El}$ mito, sobre todo aquel que se halla en el medio de la oralidad, funciona bajo las reglas del tiempo circular, es decir, un tiempo sin tiempo.

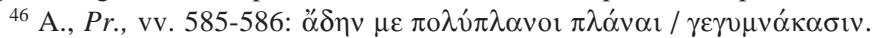


dida. De la misma manera, al estar atado por tanto tiempo, el Titán puede ser visitado por una galería infinita de personajes.

Así pues, en la versión prototípica del mito de Ío se establece el viaje como un modo que sustenta otros tópicos como el castigo (errar por todos lados), e historias colaterales como las fundaciones de ciudades y los raptos. En su viaje, la hija de Ínaco llega hasta el fin del mundo en donde se halla el Titán, y esto da pie para una reinterpretación tanto del mito como de la creación de un nuevo tópico.

En el segundo episodio (A., Pr., vv. 561-886), cuando entra Ío al escenario, descrita con cuernos de vaca, el público debió manifestar su asombro ante tal aparición, pues la intervención de la doncella imprime un nuevo ritmo a la pieza. En efecto, obsérvese que, hasta ese momento, sólo ha habido una exposición de los males que aquejan a Prometeo, y los otros personajes han sido simplemente una especie de comparsa imprescindible para exponer el núcleo de la tragedia. Al sobresalto dramático lo acompaña el misterio, es decir, la duda del porqué de la parición de Ío en escena. Las revelaciones de Prometeo son la respuesta al advenimiento y al vínculo temático entre su historia y la de Ío. El plan dramático de Esquilo se cierra de esta manera.

La presencia de Ío y las profecías que sobre ella pronuncia Prometeo modifican el tiempo narrativo. En el marco de esta escena, la coexistencia del tiempo mitológico y del tiempo en el que Esquilo está planteando y representando su pieza dramática es más evidente. ${ }^{47}$ Las características del protagonista dan pie para la modificación del tiempo, y entonces se crea un marco espacial, sui generis, en el que se manifiesta la conjun-

${ }^{47}$ Del Corno, p. 39, observa un aspecto similar en el manejo del tiempo, pero él lo relaciona con el fenómeno de la teatralización: Nel Prometeo incatenato Eschilo doveva risolvere in termini di drammaturgia una situazione che nei materiali narrativi della saga si presentava antitetica alla figura propria del tempo teatrale. Questo si concentra nell'evento, in cui si raccoglie e si esprime il significato dei fatti que hanno condotto l'eroe al momento fatale della sua esistenza. 
ción de los espacios divino y humano en cuanto Ío llega hasta donde Prometeo ha sido encadenado. Ya en esa situación, Prometeo hace honor a su nombre y manifiesta su carácter profético al revelarle a Ío lo que ha vivido y lo que habrá de venir. Para Albini, il colloquio Prometeo-Io-Coro estende la situazione, la fissa in dimensione cosmiche. ${ }^{48}$

La dimensión cósmica que propone Albini para leer el pasaje aludido se sostiene en las características esenciales del personaje mismo: Prometeo, al ser un dios, no está sujeto al tiempo, y, por lo mismo, la inmortalidad le permite hablar de una situación metafísica. Sin embargo, a la observación de Albini, hay que añadir que la temporalidad del relato entra en los terrenos propios del mito, y desde ahí se puede comprender la serie de acciones que tienen lugar en el presente. Es decir, en el momento en que Ío y Prometeo dialogan, con el coro como acompañante, el mito echa a andar el tiempo sin tiempo, por lo que las historias se hacen presentes en cualquier momento. Con ello se resemantiza el mito de acuerdo con las reglas del hic et nunc: 1) el tiempo de la representación trágica es el presente en el que el auditorio vivió bajo los postulados de la democracia, 2) la acción actual se lleva un paso atrás cuando Zeus es llamado, reiteradamente, tirano, en un sentido políticamente negativo; hay que notar que el Cronida sí está sujeto a los vaivenes del tiempo porque, al recibir el calificativo de tirano, éste funciona como un ancla que lo encuadra en una determinada situación espacial y temporal, y 3) el viaje de Ío sitúa la temporalidad fuera de cualquier referente inmediato, no sólo porque, por naturaleza, las profecías son acontecimientos en potencia, sino también porque lo dicho por Prometeo se refiere a la descripción de un mundo bárbaro y fantástico que escapa a la realidad presente del mundo ateniense de la democracia, pero que estaría latente ahí, a un lado, dividido por unas fronteras sutiles, en Asia y en África.

${ }^{48}$ Albini, p. 280. En un sentido similar se ha pronunciado Del Corno, p. 37. 
Historia y mito tienen sus propios tiempos que los determinan. Son distintos en la medida en que se comprende que el tiempo de la historia es lineal y circunscrito; en cambio, el tiempo mitológico es circular y abierto. En Prometeo encadenado, los dos tiempos se yuxtaponen, y la línea que limita hasta dónde puede llegar un tiempo y otro, con sus propios componentes, son las profecías de Prometeo. Ni siquiera cuando aparece un Tiresias en Edipo Rey o en Las Bacantes se puede hablar de una modificación del tiempo, como sucede con Prometeo encadenado. Sólo un dios con cualidades específicas como las de Prometeo podía disponer de los planos temporales para conjuntar, en su actualidad, lo que ya sucedió y lo que ha de suceder. ${ }^{49}$ Pero uno de los artilugios de la literatura está en comprender que por medio del mito, aquel que es enriquecido por la tragedia, se puede suscitar que todas las cosas, incluso las del pasado y las del presente, estén sucediendo en planos espaciales distintos hic et nunc.

El tiempo mitológico, si bien puede seguir una línea temporal histórica, es decir, una secuencia lineal, siempre se percibirá como el tiempo sin tiempo, porque no importa establecer una cronología historiográfica, sino una cronotopía que permita a los personajes moverse con una amplitud que no constriña sus acciones en el tiempo y en el espacio. Prometeo y la roca inmutable, simbólicamente forman una unidad que ve transcurrir el tiempo de los dioses y de los hombres, que, como ya se analizó, no es el mismo; al final sólo queda un tiempo indescifrable, el tiempo del mito.

Prometeo, al estar atado e inmóvil en la roca, representa, también, el aquí y ahora; a partir de este marco temporal, aparecen una serie de personajes, y la irrupción de Ío en el escenario marca el salto al tiempo propiamente mítico, o me-

\footnotetext{
49 Rehm, p. 157: Prometheus also compacts space and time, revealing the temporal limit of her anguish [sc. Ío] in terms of the distance she must travel toward her destination.
} 
tamítico para nosotros que leemos la tragedia como mito, o el mito dentro del mito, es decir, una situación metafísica para el ateniense que observó la tragedia y la vivió como mito. ${ }^{50}$ Al mismo tiempo, el Titán, en su carácter de profeta, puede traer narratológicamente a su hic et nunc el pasado y el futuro de Ío. La analepsis y la prolepsis a cargo de Prometeo desplazan los referentes narratológicos y temáticos más allá de las espectativas generadas por los mitos primigenios de los dos personajes en cuestión.

El atarse al aquí y ahora se demuestra en la interpretación que el autor de Prometeo encadenado hizo de los mitos para su tiempo presente, es decir, para el momento en que crea su tragedia: en este sentido, la palabra tirano, en el marco de la democracia, cobra una importancia capital, porque Prometeo

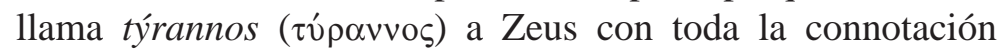
ideológica que tal palabra podía tener en la recepción del público ateniense. Además, los dioses que coinciden con Zeus (Kratos, Bía, Hermes) caracterizan al Titán como rebelde contra el sistema vigente. La tensión entre la tiranía y la democracia es el reflejo de la lucha que sostiene Zeus contra sus enemigos (Tifón y Prometeo, por ejemplo) con el fin de establecer su poder absoluto. ${ }^{51}$

Sin embargo, el mundo que transita Ío no se corresponde estrictamente hablando con ningún modelo social o ideológico conocido directamente por los atenienses, pues la doncella transformada en vaca es lanzada, como Odiseo, al mundo no griego, que es irracional y que no conoce las formas civilizadas de convivencia. Lo paradójico es que Zeus tampoco las

\footnotetext{
${ }^{50}$ Eliade, 1999, pp. 40-41, explica así este fenómeno: "por esa imitación (sc. el rito que reproduce el mito; nosotros podríamos decir, el drama que es rito y mito reproducidos al mismo tiempo) el hombre es proyectado a la época mítica en que los arquetipos fueron revelados por primera vez [...], y el que reproduce el hecho ejemplar se ve así transportado a la época mítica en que sobrevino la revelación de esa acción ejemplar".

${ }^{51}$ Cfr. supra, n. 7.
} 
reconoce y ésa es la controversia que tangencialmente plantea Prometeo, pues el Titán afirma que el Cronida ejerce la justicia de modo caprichoso, a pesar de que, con el correr del tiempo, las cosas habrán de encontrar su equilibrio, al menos en la disputa que estos dos dioses sostienen. ${ }^{52}$ Entonces, la única diferencia entre el Cronida y cualquiera de los personajes que habitan el mundo bárbaro y fantástico es el de la investidura. Si esto es así, en el viaje de Ío, a través de los pueblos y seres que conoce, conceptos como tiranía y democracia no tienen sentido alguno, pues una acción como ésta "excluye el tiempo profano y participa del tiempo mítico". ${ }^{53}$ La dramatización del viaje de Ío revela a los oídos de los espectadores un mundo salvaje y mitológico que, sin duda alguna, es parte sustancial del aspecto narratológico de la tragedia. Sin embargo, además de esto, hay una sutil sugerencia que el dramaturgo siembra en el público: la comparación entre una sociedad griega estructuralmente organizada bajo la democracia, con otra que no presenta este rasgo. El gobierno de Zeus se encamina hacia ese mundo ya rebasado en el hic et nunc en el que Prometeo dialoga con Ío, lo cual denota una barrera entre las intenciones de Zeus y el proyecto del Titán.

Así como Odiseo se encontró en su viaje con un mundo desconocido y poblado de seres que, para su imaginario y, por lo tanto, para el del auditorio inmediato de tales aventuras, fueron percibidos como mitológicos, del mismo modo Ío fue lanzada a errar por un mundo en el que la humanidad en términos estrictos era desconocida y, en varios casos, ella, que era un esperpento, se topó con seres monstruosos. Quizá por sus características, que oscilan entre lo vacuno y lo humano, Ío fue trasterrada al universo que le correspondía de acuerdo con su apariencia. Se trataba de un mundo en donde los sustentos de la naturaleza no estaban domesticados, era un espejo

\footnotetext{
${ }^{52}$ Cfr. A., $P r$., vv. 186-192.

${ }^{53}$ Eliade, 1999, p. 42. Cfr. Rehm, p. 157.
} 
de los mismos seres que allí vivían. La metamorfosis de Ío no sólo era una transformación física, sino que también colocaba al personaje en el mundo del mito fantástico; por esta razón, la doncella se convirtió, además, en el puente con otra realidad que confrontaba y definía lo griego.

Ío, en el aquí y ahora, parece retroceder a los tiempos prehistóricos, y la recepción del público de la tragedia debió evocar aquel momento mítico en los que todavía no gobernaba Zeus, por lo que, en términos narratológicos, presenciamos otro desfase propio del tiempo mitológico. En efecto, el hic et nunc de la representación trágica y uno de los motivos por los que Prometeo fue encadenado, es el progreso que el Titán simboliza. El hurto del fuego ya no es sólo una falta grave y una afrenta en detrimento del poder de Zeus, sino que, con la propuesta del creador de Prometeo encadenado, fue posible alcanzar una dimensión cósmica y metafísica del progreso:

En el hueco de un carrizo, capturé del fuego

el mananatial furtivo que, como maestro de todo arte

$\mathrm{y}$, para los mortales, como un gran patrimonio ha surgido. ${ }^{54}$

Con el regalo del fuego, Prometeo cimentó el progreso y la barbarie pasó a un segundo plano. Zeus, por su parte, borró de la faz de la tierra a seres monstruosos y formas de la naturaleza enemigas del hombre, pero de un modo violento, lo cual se constata en su enfrentamiento con Prometeo. Sin embargo, a pesar del avance que hubo en la historia del hombre, siempre permaneció un espacio donde la idea de progreso era desconocida. Pues bien, a ese mundo incivilizado y atroz, Ío fue enviada por fuerza como castigo, pero, al mismo tiempo y al igual que Odiseo, hizo un viaje de iniciación que culmina con su elevación a la inmortalidad.

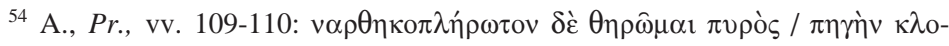

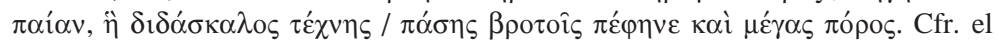
comentario de Mikalson, pp. 47-49, 94, 224, sobre las aportaciones culturales y técnicas de Prometeo en comparación con otros héroes de la tragedia.
} 
Y he aquí algo que, según hemos inquirido, no ha sido visto por los críticos de Prometeo encadenado: la confrontación entre Zeus y Prometeo es también la lucha de dos tiempos y dos formas de comprender el desarrollo humano. El anclaje que mantiene al Titán en el hic et nunc permite observar que la circularidad del tiempo se detiene y, con ello, se inaugura el tiempo del progreso. La destrucción de la raza humana que persigue Zeus es parte del plan infinito del eterno retorno, es decir, la sucesión de dioses y hombres con sus respectivos rituales es lo que determina la circularidad temporal. Bajo este esquema del tiempo no hay progreso posible. Entonces, cuando Prometeo roba el fuego fija una especie de hic et nunc del que parte un tiempo progresivo, ya no circular. La roca que detiene al Titán marca un ritmo temporal distinto. Luego de las hazañas prometeicas, ya no habría lugar en la historia para un retorno posible. Mientras Ío continúa su viaje, que terminará donde se había iniciado, en Argos, el Titán mira hacia otro horizonte, el del progreso humano, en donde ella y Zeus no tienen cabida.

Ahora bien, si, como se ha planteado, hay finalmente una reconciliación entre las dos deidades en pugna y se sella un nuevo cosmos, ${ }^{55}$ de cualquier modo habría que considerar que, a partir de Prometeo encadenado, hay una clara dicotomía en la comprensión del tiempo: por una parte, el sistema temporal que representa Zeus y que obedece al mito del eterno retorno, demostrado simbólicamente a través del viaje de Ío, y el tiempo del progreso que inaugura el Titán con el hurto del fuego y que se representa metafóricamente con la atadura a la roca. La condena de Prometeo es, paradójicamente, la simiente de una historia lineal y progresiva, y, al mismo tiempo, es espectadora de los círculos temporales en los que se ven inmersos otros personajes.

El encuentro entre Ío y Prometeo se da geográficamente en el límite del mundo. Allí, donde Prometeo ha sido encade-

${ }^{55}$ Cfr. supra, pp. 42 y 45-46. 
nado, los griegos no se atreven a poner un pie, pues es una tierra escabrosa y desolada (A., Pr., v. 2). De acuerdo con las predicciones del Titán, Ío cruzará la frontera que separa el mundo griego y el bárbaro, allí donde está la comarca escita, donde viven hombres que no conocen la agricultura y se mantienen de la guerra y del nomadismo. Estas tres características señalan con claridad que el terreno que se pisa es propio de una región incivilizada. Ío habrá de visitar otros dos pueblos considerados bárbaros, el de los cálibes y el de las amazonas.

Como se puede observar, los tres pueblos aludidos responden a diversas caracterizaciones de lo que para el imaginario griego de la época de Esquilo significaba el bárbaro en términos mitológicos e históricos. Esto es importante porque la visión que se tiene de los pueblos que no comparten la lengua y la historia de los griegos se halla a la mitad de lo que simboliza el hombre civilizado y el ser mitológico, en términos estrictos. Los bárbaros conforman pueblos que no conocen el espíritu prometeico, es decir, están fuera del progreso. Al refererirse al viaje de Ío, Rosenmeyer afirmó que la doncella era a mask for the soul of pre-Promethean man, for the terrors of human life prior to the advent of cultural progress and enlightenment. ${ }^{56} \mathrm{~A}$ pesar de que Rosenmeyer no se ocupó del tiempo mítico, su observación sirve de argumento para entender cómo el tiempo de la tragedia mezcla y yuxtapone, casi al mismo tiempo, acciones y situaciones distintas, a partir de la mirada cultural con la que son analizados pueblos diversos.

Así pues, luego de su paso por estos tres pueblos, Ío cruzará otra frontera más, aquella señalada geográficamente por el lago Meótide, el cual divide a Europa de Asia. A partir de este punto, los seres que Ío encontrará a su paso son propios del mundo mitológico para el imaginario ateniense: monstruos, seres aberrantes, violentos e incivilizados, que los oídos de los

${ }^{56}$ Rosenmeyer, pp. 65-66. 
mismos griegos percibirían ya como seres fantásticos: las gorgonas, las fórcides, los grifos y los arimaspos. ${ }^{57}$

A simple vista, parecería que Esquilo escénicamente sólo ofreció a su público un sucinto catálogo de seres fabulosos y una descripción de sus características para recordar y acentuar el sentido trágico del viaje de Ílo. ${ }^{58}$ Sin embargo, con ello abrió la puerta a una configuración mítica mucho más amplia y de alcances insospechados. En efecto, por un lado, la primera parte de la odisea de Ío se revela como un puente entre la tradición propiamente griega y aquella del llamado mundo bárbaro, en la que este último sirve de referente para comparar el progreso de Grecia en todos los sentidos; por otro lado, lo insospechado reside también en que hay una conciencia mítica más organizada que permite reutilizar los materiales temáticos y unirlos bajo un mismo sentido. Porque, en este caso, el público de aquel tiempo y el lector actual hallarían en las profecías de Prometeo un vínculo con una serie de mitos colaterales con los que se establece, por una parte, la diferenciación de los tiempos mítico e histórico y, por otro lado, la conjetura sobre lo que culturalmente definía al griego y lo distinguía de aquello que no lo era.

La siguiente frontera en el recorrido de la doncella está marcada por el río Etíope —el Nilo superior-, donde viven

\footnotetext{
${ }^{57}$ Para Croiset, pp. 3, 154-155, esta parte del viaje de Ío podría estar inspirada en las Arimaspeas, poema épico de Aristeas, sacerdote de Apolo. Sobre la vida y obra de este poeta, cfr. Hdt., IV, 13, 1-2. En Hdt., IV, 14, se refiere que compuso aquel poema épico que los griegos ahora llaman Arimaspeas. El poema, perdido en su totalidad, debió ser una fuente importante acerca del rito de la religión apolínea y trataba básicamente sobre las vivencias de Aristeas durante su viaje por el norte más extremo del mundo conocido. Llama la atención la noticia de que, en una de sus aventuras, Aristeas, que acompañaba a Apolo, iba metamorfoseado en cuervo. La incursión en tales tierras denotaría, entonces, una vinculación directa con el tópico de la metamorfosis.

Adviértase que la descripción física y ética de los arimaspos que refiere Esquilo coincide con Hdt., III, 116,1-2. Cfr., además, Duchemin, pp. 192-193, que, en general, sigue el análisis de Croiset.

${ }^{58}$ Cfr. A., Pr., vv. 700-741, 786-818, 823-876.
} 
hombres de raza negra que, si bien ya no son seres fantásticos, sí pertenecen al mundo bárbaro. ${ }^{59} \mathrm{El}$ peregrinaje, en adelante, carece de encuentros semejantes a los ya vividos en la región asiática. Ahora se trata de una descripción más bien de tipo meramente geográfico, hasta que Ío, en Canobo, será tocada por Zeus y de este contacto nacerá Epafo, quien a su vez fundará una genealogía real que gobernará Argos.

El viaje de Ío es circular tanto temporal como narrativamente; se trata, entonces, del esquema del mito de eterno retorno, pues, como ya señalabamos, de Argos había partido Ío y sus descendientes llegarán allí para gobernar. Esto significa de modo abreviado en el relato del dramaturgo, una vuelta al mundo civilizado. La idea de retorno tiene como motor el punto en el que se establece el tránsito circular para restaurar el orden. Las revelaciones de Prometeo y el castigo que padece revelan las intenciones de Zeus, lo cual permite observar la continuidad del tiempo cíclico representado por este dios. Como personaje que recién llega al poder, el Cronida debe tener en mente un camino para asegurar su gobierno. La pugna contra Prometeo es parte de ese plan y la idea es crear una raza nueva.

En esta línea del mito se halla otro nexo más con la historia de Ío, pues de ella nacerían esos hombres nuevos. Así, el motor y la protagonista del mito del eterno retorno es Ío. Desde la perspectiva prometeica se asiste a un desastre, pero desde la óptica de Zeus hay una regeneración, es decir, "la certidumbre de un nuevo comienzo [...], la réplica del comienzo absoluto, la cosmogonía", ${ }^{60}$ pues hay que comprender que, bajo los aspectos de la cosmogonía, el destruir implica, al mismo tiempo, el acto de crear: Zeus pretende continuar con el ciclo de creación de la raza humana, mientras que los actos de Prometeo son un escollo para el ritmo cosmogónico y, en

${ }^{59}$ Cfr. A., $P r$., vv. 807-815.

${ }^{60}$ Eliade, 2000, p. 71. Cfr. id., 1999, pp. 25-28. 
medio de las dos posturas, se halla Ío como catalizadora del tiempo circular (Zeus) y del tiempo lineal o progresivo (Prometeo).

El público ateniense que acudía al teatro conocía ya la sustancia temática —el mythos, según Aristóteles — ${ }^{61}$ que iba a escuchar y presenciar; sin embargo, además de los muchos intereses que habría en asistir al teatro - la catarsis, la didáctica, la política, la reflexión filosófica o el simple deleitehabría también una motivación acerca de lo que el poeta plantearía como novedad en los mitos llevados al plano trágico. Hay una diferencia sustancial entre el mero relato mítico y su recepción en la tragedia, pues los poetas dramáticos imprimieron nuevas orientaciones temáticas al mito. Y este proceso iba de la mano con los elementos propios del teatro.

El análisis aquí propuesto a la luz de la tematología permite discernir el modo en que el autor de Prometeo encadenado fue un poeta que supo leer el hic et nunc a través de la inmortalidad del mito y, a partir de ello, logró modificar la sustancia mítica aprendida, ya sea por las necesidades propias del arte dramático, ya sea porque los giros impresos al mito son las innovaciones necesarias para mover los resortes temáticos de la tragedia. La renovación del mito de Ío a través de la historia de Prometeo permite calificar al poeta como un reformador del mito a partir de la nueva concepción del ciudadano de la democracia. La tragedia de Ío es símil a la que padece Prometeo, pero el giro temático desarrollado por el poeta estableció un vínculo persuasivo entre el público y el actor, pues son éstos quienes, al estar situados en medio de una pugna divina, sufren la modificación de su tiempo y el sufrimiento no es sólo por las dolencias físicas, sino porque el hombre quiere progresar (Prometeo: historia y progreso), pero no puede abandonar del todo su naturaleza temporal (Zeus: tradición y

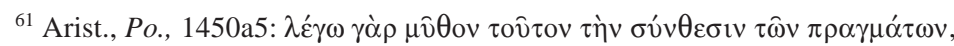

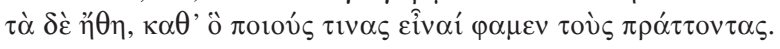


mito del eterno retorno). El tiempo, al modificarse, causa uno de los malestares más profundos en el hombre, sobre todo cuando se avizora un divorcio en los discursos que guían la historia de las sociedades. Esto sucede en Prometeo encadenado, donde Ílo se halla situada entre religión y política, en medio de la tradición y del progreso, y de la pugna que sostienen el tiempo circular y el tiempo lineal. El malestar trágico que produce el desfase y la confrontación temporal es, en suma, el resultado de la dialéctica de las ideas que se hallan tematizadas en el mito de Ío.

\section{BIBLIOGRAFÍA}

\section{Fuentes}

Aeschylus, Prometheus Bound, Mark Griffith (ed.), Cambridge, Cambridge University Press, 1988.

-, Suppliant Maidens, Persians, Prometheus, Seven against Thebes, ed. y trad. Herbert Weir Smith, Cambridge, Harvard University Press, 2001.

Aristóteles, Poética, ed. trilingüe, intr., trad. y nts. Valentín García Yebra, Madrid, Gredos, 1999.

Heródoto, Historia, intr. Francisco Rodríguez Adrados, trad. Carlos Schrader, Madrid, Gredos, 1999.

—, Historias, intr., vers., nts. y com. Arturo Ramírez Trejo, México, Universidad Nacional Autónoma de México (Bibliotheca Scriptorum Graecorum et Romanorum Mexicana), 1976.

Hesíodo, Teogonía, est. general, intr., vers. rítmica y nts. Paola Vianello de Córdova, México, Universidad Nacional Autónoma de México (Bibliotheca Scriptorum Graecorum et Romanorum Mexicana), 1986.

-, Los trabajos y los días, est. general, intr., vers. rítmica y nts. Paola Vianello de Córdova, México, Universidad Nacional Autónoma de México (Bibliotheca Scriptorum Graecorum et Romanorum Mexicana), 1979 (1986).

\section{Bibliohemerografía general}

Albini, Umberto, "La funzione di Io nel Prometeo", PP, XXX.CLXIII, 1975, pp. 278-284. 
Alsina, Clota, Teoría literaria griega, Madrid, Gredos, 1991.

Conacher, D. J., Aeschylus' Prometheus Bound. A Literary Commentary, Toronto, University of Toronto Press, 1980.

CROISET, Maurice, Eschyle. Études sur l'invention dramatique dans son théatre, Paris, "Les Belles Lettres", 1965.

Daemmrich, H. S., Themen und Motive in der Literatur, Tubinga, Francke Verlag, 1987.

Del Corno, Dario, "La drammatizzazione del mito nel Prometeo di Eschilo”, Stud. Ital., XX.I-II, 2002, pp. 34-40.

Duchemin, Jacqueline, Mythes grecs et sources orientales, Paris, "Les Belles Lettres", 1995.

Eliade, Mircea, Aspectos del mito, Barcelona, Paidós, 2000.

—, El mito del eterno retorno, Madrid, Alianza/Emecé, 1999.

FinKELBERG, Margalit, "The Geography of the Prometheus Vinctus", RhM, 141.2, 1998, pp. 119-141.

Gadamer, Hans-Georg, Estética y hermenéutica, Madrid, Tecnos, 1998.

García Gual, Carlos, Prometeo: mito y tragedia, Pamplona, Hiperión, 1979.

GNISCI, Armando, Introducción a la literatura comparada, Barcelona, Editorial Crítica, 2002.

Guillén, Claudio, The Challenge of Comparative Literature, Cambridge, Harvard University Press, 1993.

—, Entre lo uno y lo diverso, Barcelona, Crítica, 1985.

Hogan, James C., A Commentary on the Complete Greek Tragedies. Aeschylus, Chicago, University of Chicago Press, 1984.

Kitto, H. D. F., Greek Tragedy, New York, Routledge, 2002.

Lanza, D., Il tiranno e il suo pubblico, Torino, Liguori Editore, 1977.

Lloyd-Jones, Hugh, “Zeus in Aeschylus”, JHS, 76, 1956, pp. 55-67.

LóPez Férez, J. A., Historia de la Literatura Griega, Madrid, Cátedra, 1988.

Mikalson, Jon D., Honor Thy Gods. Popular Religion in Greek Tragedy, Chapel Hill, The University of North Carolina Press, 1991.

Pichois, Claude, y André-M. Rousseau, La literatura comparada, Madrid, Gredos, 1967.

ReinHardt, Karl, Eschyle. Euripide, Paris, Gallimard, 1972.

Renm, Rush, The Play of Space. Spatial Transformation in Greek Tragedy, Princeton, Princeton University Press, 2002.

Romilly, Jacqueline de, La crainte et l'angoisse dans le théatre d'Eschyle, Paris, "Les Belles Lettres", 1971.

—, La tragédie grecque, Paris, Presses Universitaires de France, 1973.

Rosenmeyer, T. G., The Masks of Tragedy, Austin, Austin University Press, 1963. 
Solmsen, Friedrich, Hesiod and Aeschylus, New York, Cornell University Press, 1995.

TAPLIN, Oliver, The Stagecraft of Aeschylus, Oxford, Oxford University Press, 1989.

Thomson, George, Aeschylus and Athens, London, Lawrence \& Wishart, 1946.

Trocchi. Véase GNisci.

Trousson, R., Un problème de littérature comparée: les études des thèmes, Paris, Minard, 1965.

Vianello. Véase Hesíodo.

White, Stephen, "Io's world: intimations of theodicy in Prometheus Bound", JHS, 121, 2002, pp. 107-140.

Wilamowitz-MoellendorfF, Ulrich von, Aischylos Interpretationem, Berlin, Weidmannsche Buchhandlung, 1914. 